\title{
Surveillance of severe neonatal hyperbilirubinemia: a view from south of the border
}

\author{
M. Jeffrey Maisels, Thomas B. Newman \\ $\infty \quad$ See related article page 587
}

I $\mathrm{n}$ this issue of the $C M A J$, Sgro and colleagues ${ }^{1}$ report their identification, through the Canadian Paediatric Surveillance Program (CPSP), of 258 infants who had severe neonatal hyperbilirubinemia (total serum bilirubin level greater than $425 \mu \mathrm{mol} / \mathrm{L}$ or receipt of exchange transfusion) from 2002 to 2004. Their estimated incidence was I in 2480 live births. Because the CPSP is based on voluntary reporting, this estimate is almost certainly conservative. In contrast, a serum bilirubin level of $428 \mu \mathrm{mol} / \mathrm{L}$ or greater was reported in I in 700 live births in a $1995-1996$ birth cohort in northern California ${ }^{2}$ and in about $\mathrm{I}$ in 625 live births in the 1959-1966 Collaborative Perinatal Project. ${ }^{3}$ Thus, the CPSP data do not suggest a "resurgence" of severe neonatal hyperbilirubinemia.

It would have been helpful if Sgro and colleagues had provided more information about the study subjects and their diagnostic evaluation. How do the subjects compare with the population from which they arose in terms of ethnic background, breast-feeding status, gestational age and maternal age? For the laboratory tests in their Table 2, only the numbers with abnormal results are listed, not the numbers tested. If a minority of the infants were tested, the proportion with abnormal test results could be misleading. For example, in the Jaundice and Infant Feeding Study, which involved infants with a serum bilirubin level of $428 \mu \mathrm{mol} / \mathrm{L}$ or greater, glucose-6phosphate dehydrogenase (G6PD) deficiency was identified in only 4 (3\%) of I 40 infants, but only I 5 were tested for it. ${ }^{4}$

Some of the data Sgro and colleagues report are quite puzzling. Severe neonatal hyperbilirubinemia due to $\mathrm{ABO}$ incompatibility is extremely rare unless the mother has group O blood. ${ }^{5}$ This makes it difficult to explain how 16 of the 48 infants whose elevated bilirubin level was attributed to $\mathrm{ABO}$ incompatibility were born to mothers whose blood group was not $\mathrm{O}$. If the blood groups are correct, one must assume that some other cause was responsible for the severe jaundice in these infants.

The authors did not provide data on the incidence of kernicterus, although we understand that a similar surveillance program for kernicterus in Canada has been initiated. If one - assumes that all 13 infants who had "clinically important neurologic abnormalities at final discharge" represent cases of kernicterus, this would be an incidence of $\mathrm{I} 3$ per 600 o00, or about 2 per 100 ooo live births, which is similar to the peak incidence of I in 53000 live births recently reported from Denmark. ${ }^{6}$

The American Academy of Pediatrics (AAP) has emphasized the importance of identifying both clinical and laboratory risk

factors that can help to quantify the risk of subsequent development of severe hyperbilirubinemia. Predischarge risk assessment is necessary, because in most infants discharged before 48 hours, the bilirubin level has not yet peaked. For the infants who, after the initial discharge, were readmitted to hospital with a total serum bilirubin level greater than $425 \mu \mathrm{mol} / \mathrm{L}$, the problem appears to have been one of appropriate surveillance, follow-up and intervention. It is remarkable, however, that 73 (28.3\%) of the 258 infants experienced severe hyperbilirubinemia before their initial discharge. In a northern California birth cohort, only $7 \%$ of the infants with a peak total serum bilirubin level of $427 \mu \mathrm{mol} / \mathrm{L}$ or greater had not been discharged. ${ }^{2} \mathrm{~A}$ possible explanation for these differences is the inclusion by Sgro

\section{Combining predischarge bilirubin measurements with} risk factors provides the best
estimate of the risk of subsequent hyperbilirubinemia.

and colleagues of infants who received an exchange transfusion, whether or not their peak bilirubin level exceeded $425 \mu \mathrm{mol} / \mathrm{L}$. It would be of interest to know how many of the subjects were included based only on their receipt of an exchange transfusion, and how many underwent the transfusion because of failure of intensive phototherapy or because the phototherapy was too little or too late. When phototherapy is used according to published guidelines, ${ }^{7}$ bilirubin levels above $425 \mu \mathrm{mol} / \mathrm{L}$ should rarely occur, and exchange transfusions should rarely be needed. ${ }^{8}$

The authors note that an infant with a total serum bilirubin level of more than $425 \mu \mathrm{mol} / \mathrm{L}$ is "thought to be at high risk of kernicterus." Although some cases of kernicterus have been described at these, or lower levels, ${ }^{9,10}$ they are very unusual. More than three-quarters of the infants in the kernicterus registry had a total serum bilirubin level of $515 \mu \mathrm{mol} / \mathrm{L}$ or greater, 
and two-thirds had a level exceeding $600 \mu \mathrm{mol} / \mathrm{L} .{ }^{9}$ Furthermore, in a study involving 130 infants with a level of 428 $\mu \mathrm{mol} / \mathrm{L}$ or greater and followed for $2-5$ years, Newman and colleagues found no evidence of any behavioural, cognitive or neurologic deficits attributable to bilirubin toxicity. ${ }^{4}$ This does not mean that we should encourage physicians to allow infants to reach such levels, but it does suggest that when such levels are detected, the outcome is very likely to be good if appropriate treatment is initiated promptly.

Sgro and colleagues also note that it is often difficult for family practitioners or other primary care providers to evaluate all infants within $48-72$ hours of discharge, as previously recommended by the AAP. ${ }^{11}$ Currently, the AAP recommends that any infant discharged before 72 hours should be seen within 2 days after discharge and that a systematic assessment of risk factors before discharge will help to identify infants who are at significant risk of hyperbilirubinemia. ${ }^{7,12}$ If significant risk factors are present and the infant cannot be seen within a day or 2 after discharge, the practitioner has only 2 options: either the infant can be kept in the hospital for another day or, failing this, an outpatient bilirubin level can be measured a day or 2 following discharge and the result communicated to the practitioner. Whichever of these approaches is chosen, it is simply no longer acceptable for an infant delivered at 36 weeks who is breast-feeding to be sent home at 48 hours without follow-up within a day or 2. Even the documentation of a relatively low bilirubin level before discharge is no guarantee that the infant will not subsequently experience severe jaundice, ${ }^{13}$ and in an infant with G6PD deficiency, there is always the possibility of a later sudden rise in the bilirubin level that cannot be predicted.

The data gathered by the CPSP do not permit a "root cause" analysis of why some infants continue to have bilirubin levels of more than $425 \mu \mathrm{mol} / \mathrm{L}$. It is likely, however, that, although some (perhaps many) of these infants were seen in a timely fashion at follow-up visits (and might have had jaundice), no bilirubin level was obtained. Visual inspection of newborns to determine the degree of jaundice is subject to error ${ }^{14}$ but short of requiring that the total serum bilirubin level be obtained for every infant who shows any sign of jaundice at a follow-up visit, there is no simple answer to this problem. Use of transcutaneous measurements ${ }^{15}$ would certainly help, but the cost of these instruments is currently prohibitive for many practitioners.

Sgro and colleagues recommend that a blood type and Coombs' test be performed on the cord blood of all infants of mothers with group O blood, but the results of such screening, whether positive or negative, do not vitiate the importance of appropriate follow-up.

More intensive monitoring of serum bilirubin levels might increase the number of readmissions for phototherapy, but if this strategy prevented kernicterus, it would be a worthwhile intervention. Sgro and colleagues recommend that any infant who appears to have jaundice or has risk factors should have his or her serum bilirubin level measured before discharge and that repeat bilirubin testing should be based on the predischarge measurement. It is important, however, to look at the patient as well as the laboratory value: even a low-risk patient should have repeat bilirubin testing at the follow-up visit if there is significant jaundice. Combining predischarge bilirubin measurements with risk factors provides the best estimate of the risk of subsequent hyperbilirubinemia, ${ }^{12}$ but such an evaluation will not help if follow-up and intervention are inadequate. It will also not change the risk for infants who remain in the nursery, in whom more than minimal jaundice should dictate the need for a bilirubin measurement and appropriate intervention before excessive levels occur.

As noted by Sgro and colleagues, preventing severe hyperbilirubinemia requires a consistent effort by all caregivers to ensure early identification, risk assessment and appropriate follow-up. Although no system is perfect, this should help to reduce the number of infants who experience severe hyperbilirubinemia and, more importantly, kernicterus.

\section{This article has been peer reviewed.}

Jeffrey Maisels is with the Department of Pediatrics, William Beaumont Hospital, Royal Oak, Mich.; Thomas Newman is with the Departments of Epidemiology and Biostatistics and of Pediatrics, University of California San Francisco, San Francisco, Calif.

Competing interests: None declared.

Contributors: Both authors contributed substantially to the writing and revision of the manuscript and gave final approval of the version to be published.

\section{REFERENCES}

I. Sgro M, Campbell D, Shah V. Incidence and causes of severe neonatal hyperbilirubinemia in Canada. CMAJ 2006;175(6):587-90.

2. Newman TB, Xiong B, Gonzales VM, et al. Prediction and prevention of extreme neonatal hyperbilirubinemia in a mature health maintenance organization. Arch Pediatr Adolesc Med 2000;154:II40-7.

3. Newman TB, Klebanoff MA. Neonatal hyperbilirubinemia and long-term outcome: another look at the collaborative perinatal project. Pediatrics 1993;92:65I-7.

4. Newman TB, Liljestrand P, Jeremy RJ, et al. Outcomes among newborns with total serum bilirubin levels of $25 \mathrm{mg}$ per deciliter or more. NEngl J Med 2006;354:I889-900.

5. Ozolek J, Watchko J, Mimouni F. Prevalence and lack of clinical significance of blood group incompatibility in mothers with blood type A or B. J Pediatr 1994;125:87-9I.

6. Ebbesen F. Recurrence of kernicterus in term and near-term infants in Denmark. Acta Paediatr 2000;89:1213-7.

7. American Academy of Pediatrics Subcommittee on Hyperbilirubinemia. Management of hyperbilirubinemia in the newborn infant 35 or more weeks of gestation. Pediatrics 2004;II4:297-316.

8. McDonagh AF, Maisels MJ. Bilirubin unbound: Deja vu all over again? Pediatrics 2006;117:523-5.

9. Bhutani VK, Johnson LH, Maisels MJ, et al. Kernicterus: epidemiological strategies for its prevention through systems-based approaches. J Perinatol 2004; 24:650-62.

Io. Ip S, Chung M, Kulig J, et al. An evidence-based review of important issues concerning neonatal hyperbilirubinemia. Pediatrics 2004;II4:eI30-53.

II. American Academy of Pediatrics. Provisional Committee for Quality Improvement and Subcommittee on Hyperbilirubinemia. Practice parameter: management of hyperbilirubinemia in the healthy term newborn. Pediatrics I994;94:558-62.

12. Newman TB, Liljestrand P, Escobar GJ. Combining clinical risk factors with bilirubin levels to predict hyperbilirubinemia in newborns. Arch Pediatr Adolesc Med 2005;I59:113-9.

I3. Maisels MJ, Kring EA. Routine transcutaneous bilirubin (TcB) measurements in the nursery predict the risk of subsequent hyperbilirubinemia [abstract 5575.479]. Pediatric Academic Societies annual meeting; San Francisco; 2006 Apr 29-May 2. Available: www.abstracts2view.com/pas/index.php (accessed 2006 Aug 16).

I4. Davidson LT, Merritt KK, Weech AA. Hyperbilirubinemia in the newborn. Am J Dis Child i94r;6r:958-80.

I5. Maisels MJ, Ostrea EJ Jr, Touch S, et al. Evaluation of a new transcutaneous bilirubinometer. Pediatrics 2004; II3:1628-35.

Correspondence to: Dr. M. Jeffrey Maisels, Department of Pediatrics, William Beaumont Hospital, 360 I W I3 Mile Rd., Royal Oak MI 48073, USA; fax 248 551-5998; jmaisels@beaumont.edu; or Dr. Thomas B. Newman, Departments of Epidemiology and Biostatistics and of Pediatrics, School of Medicine, University of California San Francisco, San Francisco CA 94143-0560, USA; fax 415 514-8150; newman@epi.ucsf.edu 